\title{
Concept Study for a Mach 6 Transport Aircraft
}

\author{
J.M.A. Longo $^{1}$, R. Dittrich, D. Banuti, M. Sippel ${ }^{*}$, J. Klevanski ${ }^{*}$, U. Atanassov ${ }^{*}$ \\ German Aerospace Center (DLR), Institute of Aerodynamics and Flow Technology, 38108 Braunschweig, Germany \\ ${ }^{*}$ German Aerospace Center (DLR), Institute of Space Systems, 28359 Bremen, Germany \\ G. Carrier, Ph. Duveau, I. Salah El Din, R. Thepot \\ Office National d'Etudes et de Recherches Aérospatiales (ONERA), FR-92190 Meudon, France \\ A. Loubeau, F. Coulouvrat \\ Université Pierre et Marie Curie (UPMC), 4 place Jussieu 75252 Paris cedex 05, France \\ R. Jarlas, H. Rabia, \\ Swedis Defence Research Agency, (FOI), 16490 Stockholm, Swedish \\ D. Perigo, J. Steelant \\ European Space Agency Technical Center, (ESA-ESTEC), 2200 AG Noordwijk ZH, the Netherland
}

\begin{abstract}
A conceptual study is here presented and discussed on the possibility to transport 200 passengers over a distance of about $7000 \mathrm{~km}$ in a nominal point-to-point mission through the Atlantic (either London-New York or London-Rio) at a cruise Mach number of 6 and an altitude about $30 \mathrm{~km}$. The aim of the study is not to design a specific airplane but to explore today's state of the art technology limits to realize such kind of concept, i.e. to identify if such a mission could succeed today. Because of the challenge the mission poses, its is being optimised with the major disciplines involved by means of Multi-Disciplinary Optimisation (MDO) tools as a way to realize an optimum integrated airframe/propulsion aircraft. The environmental impact is being analysed in terms of the resulting sonic boom. No experimental data but CFD results by means of independent assessments has been generated. The study indicates that today the available technology provides with sufficient maturity to accomplish with the mission in areas like aerodynamic and thermal resistance materials but in others like sonic boom mitigation it is required a deeper insight in the physics. Finally while the present investigation clear identify that complex designs involving large amount of variables from different disciplines could be only possible via MDO/MDA strategies, today such processes still suffer on lack of robustness of the involved tools.
\end{abstract}

\section{Introduction}

Already more than sixty years ago, in March 1947, for the first time an airplane was able to flight beyond the sonic barrier. Yet, despite the early promise of supersonic developments and the routine Mach 1-plus capabilities of today frontline combat aircrafts, it could be argued the wider potential benefits of faster-than-sound travel have failed to materialize. Indeed, the touchdown of the last Concorde, in November 2003, effectively represents the first time in human history that progress in travel time has gone into reverse. However, current thinking to develop a high-speed transport aircraft by very high ecologic and economic requirements is based on continued air travel growth since part of this growth also asks for reduced travel times. The potential to reduce overall travel times by reducing the ground service period is limited. Therefore, this demand requests for high-speed air transport. Major impediments to high-speed transport development are environmental impact (take-off/landing noise, sonic boom and ozone depletion), light-weight high-temperature materials, aerodynamic and propulsion efficiency. These points are all critically dependent on the vehicle configuration. Indeed, propulsion and aerodynamic design must be efficiently integrated combined with lightweight high temperature resistant materials necessary in order to realize a globally performant vehicle. Designs with high aerodynamic efficiency tend to demand higher performance materials for example by involving thin flat shapes that are inherently inefficient structures resulting in high material stresses and so on. Further, at these high speeds, classical turbo-jet engines need to be replaced by advanced air-breathing engines. Therefore, there is a strong need to identify critical technologies for both the external airframe and the propulsion units such as lightweight airframe components, lightweight engine components, novel cooling techniques for airframe and engine, modelling and validation of numerical simulation tools for combustion physics, dedicated

${ }^{1}$ Head Spacecraft Branch, Lilienthalplatz 7, 38108 Braunschweig, Jose.Longo@dlr.de 
combustion and aerodynamic experiments, aerodynamic and material interaction modelling and verification; computational fluid dynamic tools for advanced turbulence \& transition models among others.

To overcome that situation the European Union decided to support two proposals presented in 2005 and 2006, by large consortiums of major European institutions on high speed flow, under the coordination of the European Space Agency, ESA, through its European Technology Centre, ESTEC. The proposed research programs are the Long term Advanced Propulsion Concepts And Technologies (LAPCAT) and the Aerodynamic and Thermal Load interactions with Lightweight Advanced materials for high Speed flight (ATLLAS). These two programs target on sustained hypersonic flight where the former focuses on propulsion concepts and the latter on high temperature resistant materials which can withstand ultra high temperatures and heat fluxes enabling high-speed flight above Mach 3. Both programs benefit from the participation of 7 European countries and 19 institutions with a broad know-how in these fields. Further, the system requirements necessary to define realistically the research constraints and directions as well as to assess the results are derived from six specific vehicle concepts, which are also integral part of the studies, i.e. (1) a 300-seat SST concept designed to meet an operational requirement of Mach 3 flight over a $7000 \mathrm{~km}$ range; (2) a Mach 4.5 design based around a variable cycle including turbofan technology; (3) a Mach 5 pre-cooled, 400Tn-300 passenger vehicle; (4) a turbo-ram-jet Mach 6 aircraft; (5) a cruise flight Mach number 8.0 vehicle using a hydrogen-fuelled dual-mode scramjet and finally (6) a rocket propelled 50 seats space liner. Here a conceptual study is presented exploring the possibility to transport 200 passengers over a distance of about $7000 \mathrm{~km}$ in a nominal point-to-point mission through the Atlantic (either London-New York or London-Rio) at a cruise Mach number of 6 and an altitude of about $30 \mathrm{~km}$. The dramatic fall in lift to drag ratio at supersonic/hypersonic speeds and the poor propulsion efficiency during acceleration, not compensated by the better propulsion efficiency during cruise, requires a design with highly efficient propulsion-airframe integration to avoid high fuel consumption. Previous supersonic research in Europe was mainly focused on cruise Mach numbers similar to Concorde, around $\mathrm{Ma}=2$. The challenges in designing a transport aircraft for a cruise Mach number of 6 largely exceed those recognised to achieve flight in the conventional supersonic regime. Between the seventies and the nineties, the SR71, a military high altitude reconnaissance aircraft (i.e. a high altitude high cruise Mach number) was operating at Mach 3. On the other side, no operational Mach 6 aircraft has existed at all at any time. The only experimental Mach 6 vehicle to have flown is the X-15 but it was conceived to perform an acceleration climb by a non-airbreathing engine followed by an almost parabolic non-powered descent flight for a total duration of about 1 minute, i.e. a mission far a way from a high altitude high cruise Mach number. Indeed, still today there is no clear evidence if one can realize a high altitude Mach 6 aircraft.

The target of the study is not to maximize the efficiency of the mission but to identify if such a mission could be successful today. Further, to minimize cost and time, the study departs from the most "close to the target" configuration selected by the working team from a group of configurations identified in available literature. A multiple-point MDO process relying on high fidelity tools for flight phase models involving the disciplines of aerodynamics, structures and flight mechanics, is being developed during the study, to design a high-speed transport aircraft for a cruise Mach number of $\mathrm{Ma}=6$, with sufficient capacity for transonic acceleration and landing. This MDO takes into account a specific propulsion system by using integral performance data and also takes into account a structural model. Further, trajectory assessment, internal layout and mass estimation are provided in the study. A second MDO process is being developed and applied for the design of the air-intake, to satisfy the demands of the propulsion system. The pre-optimized forebody will be integrated in a final multiple-point airframe MDO loop, allowing a reduction in the overall computational effort. Since no experimental data are planned for the present study, two evaluations of the configuration are scheduled at the early stage and at the end of the study by means of independent CFD results. This process uses a Navier-Stokes code previously validated with experimental data available for the base line configuration. Finally, the environmental impact of such a vehicle is focused onto specific analyses of the resulting sonic boom, accounting for atmospheric dispersion at high altitudes. From the aerodynamic point of view it is clear that in order to realize cruise at hypersonic speed, high lift over drag ratios must be achieved, but that is in opposition to sonic-boom mitigation guide-lines requirements. The concept of boom minimization is based on suppressing the coalescence of multiple secondary shock waves caused by the airplane in supersonic/hypersonic flight, so that the overpressure at ground level is reduced. This can be achieved through the manipulation of aircraft's design characteristics, resulting in an optimised wave pressure signature with significant sonic boom loudness attenuation. Advanced low-boom configurations may be achieved by a more uniform lift distribution stretched over a longer length, so that the sonic boom maintains its weaker mid-field features with a lower bow shock. In order to obtain adequate boom loudness suppression, the area distribution of an aircraft must be carefully determined aerodynamically but, such advanced low-boom designs induce drag penalties. An integration 
of low-boom design parameters within the MDO process is not foreseen in the frame of the present investigation but could be a rational next step for a future study. The following chapters present an overview of the working-team individual contributions to the study, while the present results for the MDO process can be still considered as preliminary since the project continues running.

\section{Airplane Shape Definition by Multidisciplinary Multiple-Point Design Optimization}

In the past different approaches were used to realize high lift over drag configurations resulting in different designs like 'waverider' concepts or long slender fuselage designs with highly swept wing leading edges. Unfortunately most of them stayed in theoretical status due to the huge amount of physical and technical problems for high aerodynamic performance, feasible airframe structure design, efficient propulsion integration or light, robust material applications. Therefore the design should be approached by means of a multidisciplinary optimisation. However and in order to save some time, the study is initiated reviewing the literature of past projects to find out an initial configuration as close as possible to the ATLLAS Mach 6 targets. In the eighties the HYCAT1A airplane was designed for a 7000km flight range taking 200 passengers on board, i.e. similar mission objectives than the ATLLAS one, and a huge amount of technical data like structural masses and wind tunnel tests are today available in open literature [1-2]. With a fuselage of 105 meter long and a span wise of 28 meters it presents a promising compromise between hypersonic and subsonic performance as well as good trim capabilities, both major requirements for future hypersonic aircrafts. Also favour the HYCAT-1A selection the fact it has classical horizontal tail, characteristic sharp forebody leading edges and as like is thought for the ATLLAS Mach 6, it was designed to be propelled by a combined turbojet-ramjet engine based on hydrogen fuel. However, being strictly here is not used the HYCAT-1A vehicle but based on published drawing of such airplane, a vehicle configuration is here build up resembling to some extend such geometry. The ATLLAS Mach 6 reference design configuration, ATLLAS M6 RD, has a fuselage characterized by elliptic shaped cross sections added by a sharp leading edge for the outer forebody which merges to the wing leading edge. This forebody shape is derived from the waverider principles offering high lift to drag ratios. Initially wing and elevator have double trapezium profiles. Figure 1 presents computed CFD aerodynamic performances of this configuration as a function of the Mach numbers range compared with published data of other projects with similar mission objectives.

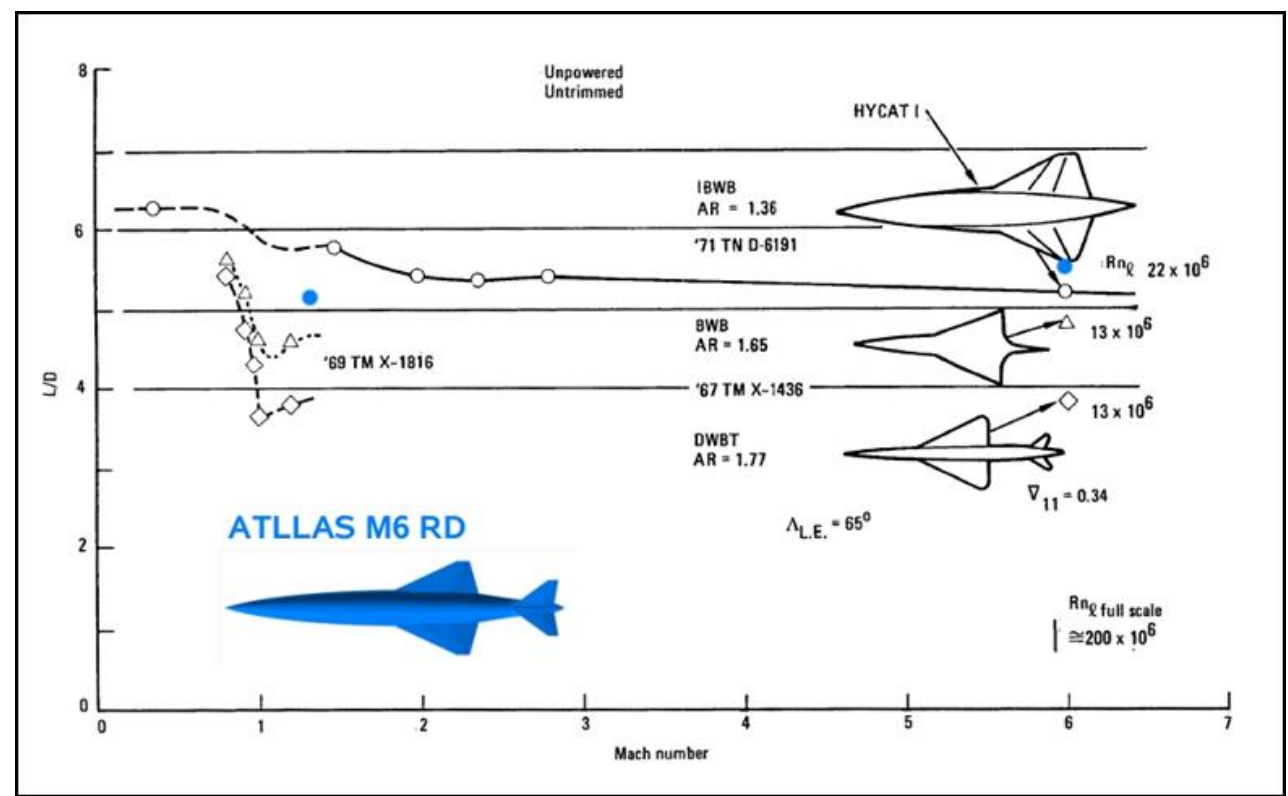

Fig. 1: Aerodynamic performances of the ATLLAS Mach 6 reference design configuration, ATLLAS M6 RD (blued dots), compared with published data for different airplanes with similar mission objectives.

It turns out, the ATLLAS M6 RD not only resembles geometrically the HYCAT-1A but also its aerodynamic performances are similar. Further, completes the data base of the ATLLAS M6 RD a mass budget estimation, turbojet-ramjet engine performance, mission profile arrangement, aerodynamic CFD calculations in subsonic, transonic and hypersonic, dynamic FEM analyses and trim capability calculations . 


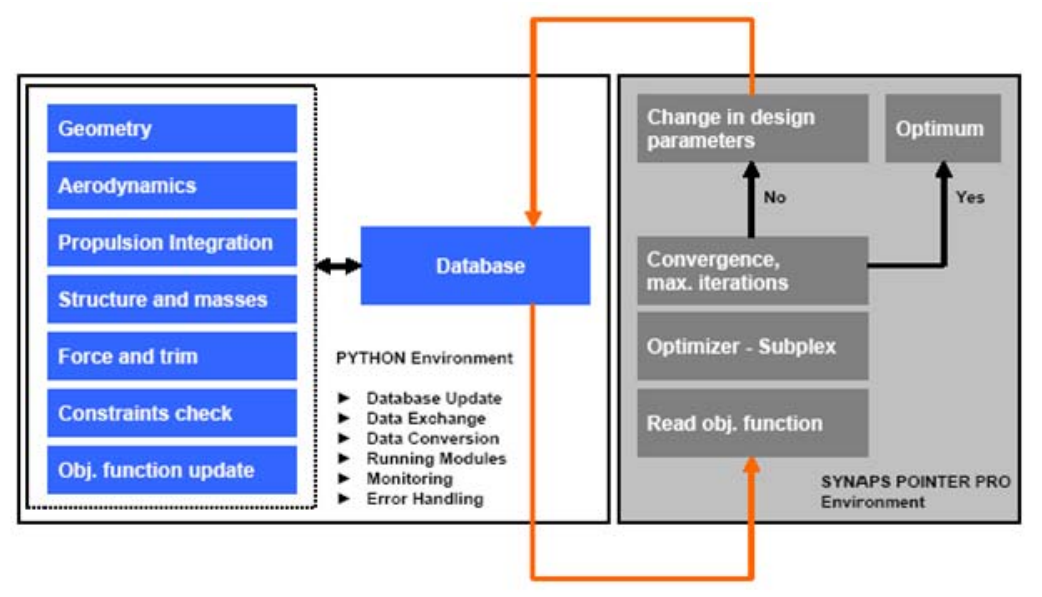

Fig. 2: Airframe-MDO works flow (DLR-AS).

The principle work flow for the MDO tool developed by DLR-AS is shown in Fig. 2 and consists of several modules for different subtasks which are added to a functional chain where at the end a defined objective function is updated [3]. There are modules for parameterized geometry generation, mass modelling for component masses and centre of gravity computation, CFD grid generation, numerical aerodynamic flow solving, thrust and trim capability determination, FEM grid generation and dynamic structure analysis, constraints check and objective function update. Most of the modules are mission-flight depending e.g. transonic or cruise condition. Further, the propulsion system is integrated in the MDO in a form that intake and nozzle-flow are computed by means of CFD as shown Fig. 3, but the combustion chamber is covered as a black box with given properties so the gross thrust is determined. Indeed, to perform the computations, engine parameters obtained by DLR-SART are used to provide the flow solver with the flow properties required at the entrance and exit of both turbo and ram-jet engine types (Fig.4). Also, the specific fuel consumption is calculated from the net thrust given by intake, combustion chamber and nozzle force and fuel mass flow for the current engine mode. This is needed for later range estimation. Finally, along the flight envelope the MDO has to take into account not only the differences on engine-performances but also intake and nozzle engine-geometrical changes due to changes in flow regime.

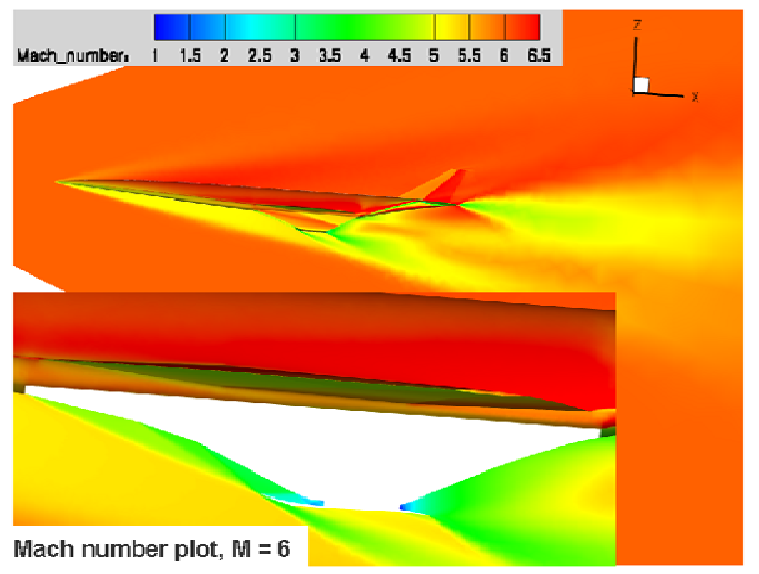

Fig. 3: CFD computation of the resulting flow field of the ATLLAS M6 RD during cruise (DLR-AS). Top: full view. Bottom: detail view of the flow around the engine. 


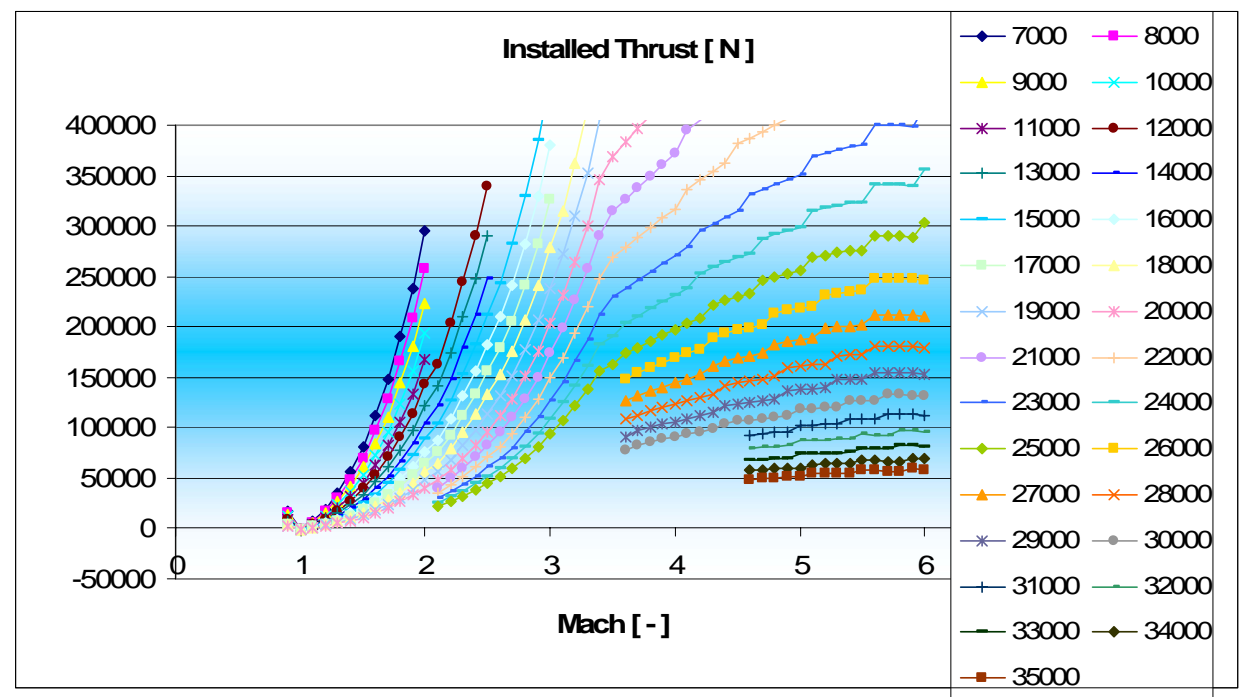

Fig. 4: Turbo-Ram-Jet Performances Data. (DLR-SART)

The numerical flow solver code TAU [4] of DLR is one of the main items of the multidisciplinary analysis tool. It is a three-dimensional Reynolds-averaged Navier-Stokes solver based on a finite volume method delivering flow properties in a wide range of Mach numbers from low subsonic up to super-orbital re-entry velocities. Both structured and unstructured grids are supported. To reduce computational effort for the flow solver, the Euler equations combined with a turbulent flat plate model for skin friction estimation is preferred instead of NavierStokes solutions. With this method three main parameters of the system are defined: first, the resulting force coefficient in flight direction; second, the aerodynamic lift to drag ratio and third, the geometric point where all pitch moments are equal to zero. Indeed, the force balance is calculated from the CFD results plus a force model for the combustion chamber including the gross thrust and small intake corrections as presented in Fig. 5. Since forces for intake and nozzle are already included in the CFD calculation, the main force coefficients for lift, drag, thrust and pitch moment are determined. Hence, the determination of the pressure point is possible and comparing the location of this point with respect to the centre of gravity gives trim capability of the configuration. Here the aerodynamic efficiency of a deflected horizontal stabilizer plays an important role. As Fig. $\mathbf{6}$ shows, the horizontal tail decreases its trim capability at high Mach numbers.

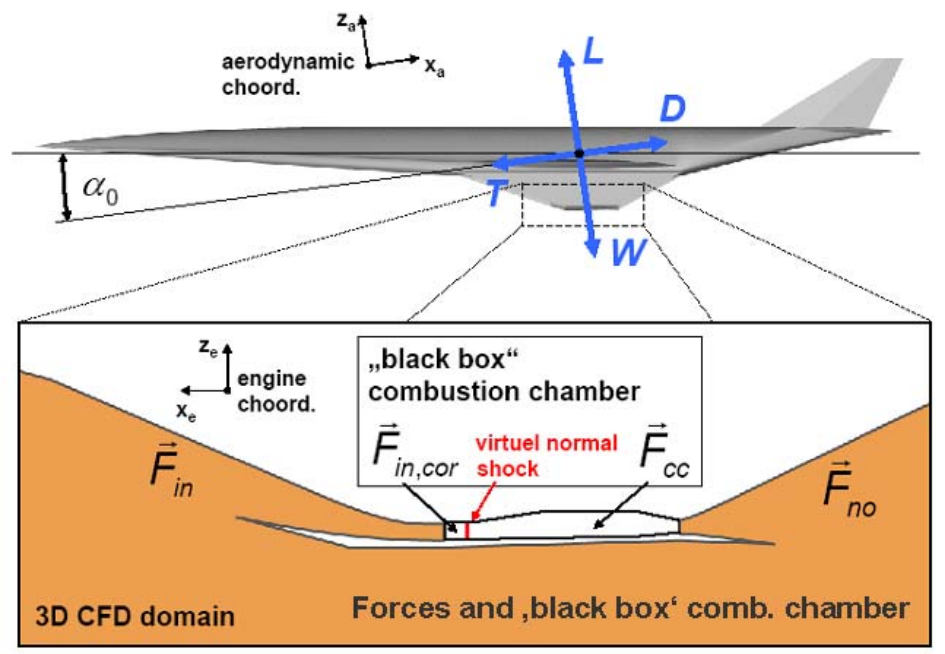

Fig. 5: Scheme of force-balance used for trim estimations (DLR-AS). 


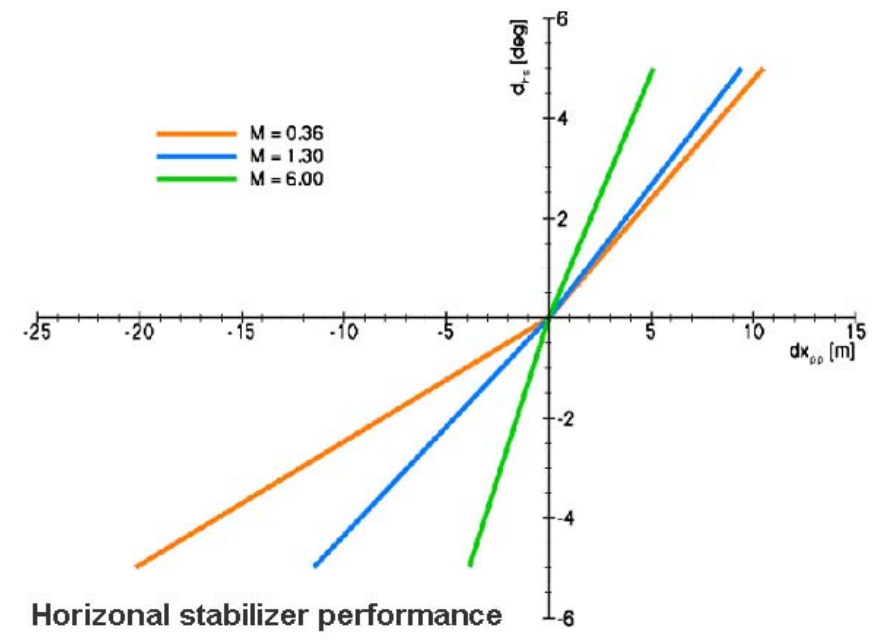

Fig. 6: Impact of the horizontal tail deflection on centre of pressure location for different Mach numbers.

Also, to speed up the MDO process special methods are developed like a modular mesh generation procedure which strongly reduces meshing time. Indeed, the geometry generation is one of the major modules of the MDO tool due to most of the engaged modules are depending on the geometry. For the geometry generation an own tool is developed based on NURBS (Non Uniform Rational B-Splines) curves described by a set of control points [5]. A certain number of NURBS curves are arranged in 3D-space resulting in a surface. The geometry is divided in several surfaces and changing NURBS attributes offers different kinds of surface interfaces from complete smooth to kink. The geometry description is completely parameterized hence the airframe is controlled by about 100 parameters and the engine by 40 parameters. The tool allows global and local geometry changes modifying NURBS control points and guaranties water closed geometry. Additionally inner surfaces for front and rear inner tanks and passenger cabin needed for mass estimation are created. Furthermore the geometry tool can be used directly for structure model node creation. Finally, the geometry changes resulting during the MDO process requires a re-meshing for the CFD computation within every optimization loop. Therefore the commercial unstructured grid generator CENTAUR [6] is used. For higher accuracy grids with about 1.8 million nodes are used whereas almost half of the nodes are located in the engine zone. Suitable source placement guaranties fix mesh refinement for certain local geometry parts like wing leading edges. It has to be noted that for a multi-point MDO process also multiple meshes are needed due to different far field requirements, engine operating modes and horizontal stabilizer deflections. It turns out CFD grid generation is one of the main driver for the overall loop time. To strongly reduce the meshing time, a special modular grid generation procedure is developed by splitting the 3D-field around the configuration into several zones which can be re-meshed independently as is shown in Fig. 7. Indeed, in the MDO tool commercial software as well as own developed source codes are used. All modules are embedded in a new and fully automated PYHTON environment taking over running and monitoring of modules, data exchange and conversion, machine communication and database update. The modular concept of the MDO process allows simple removing, adding and modifying of several modules. The MDO tool is linked to the commercial software SYNAPS POINTER PRO [7] which offers several types of optimizers, like scanner, gradient based or genetic methods. In the presented MDO the Subplex optimizer, a function ranking method, is favoured. The Subplex optimizer is based on the Nelder-Mead simplex (NMS) method which is often recommended as best optimizer for noisy function due to a function value ranking system which is not depending on absolute objective function values. Furthermore no parameter sensitivity study is necessary, but NMS is limited to low dimensional problems $(n<6)$. The Subplex optimizer now makes the NMS feasible for high dimensional problems by determining subspaces of the parameter space where the NMS can be applied: a so called subplex cycle is evaluated. Convergence can be observed after 3 to 5 subplex cycles [8]. 


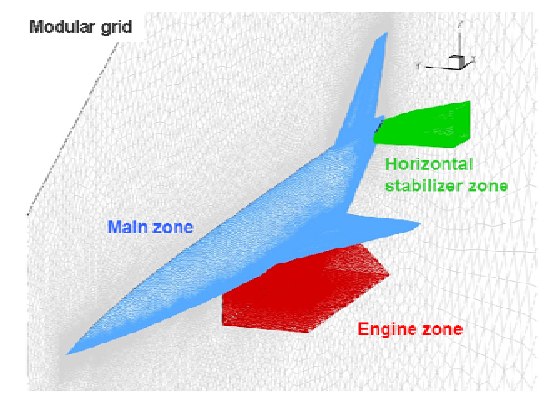

Fig. 7: Modular grid generation arrange strategy showing the different modules (DLR-AS).

As objective function for the MDO process it is chosen the range, due to linkage of aerodynamic and engine performance as well as fuel and operating empty mass. For a 1-point MDO the Breguet range is used but also new range estimations for multiple cruise points are evaluated by integration of the basic range equation for nonaccelerated horizontal flight. Indeed, except from take-off and landing, two flight points of mission profile are identified as critical and hence suitable for the optimisation: start of cruise at Mach 6 and transonic ascent at Mach 1.3. Both points are very important for the overall design and have different requirements. The cruise mode has to be characterized by a high lift to drag ratio, low fuel consumption and fulfilling the trim conditions. Due to the peak of wave drag at transonic Mach numbers the priority is set in the availability of sufficient thrust. Minimizing thrust in transonic flight means more fuel available for cruise. It has to be remarked that hypersonic vehicles can consume 40$50 \%$ of overall fuel mass during ascent up to cruise altitude. Both points have big impact on the maximum cruise distance which is defined here as goal function for the MDO. Further, the configuration constraints which can not be found in the range equation are added to the objective function in form of a penalty function which gives the final objective function. Hence the constrained optimization problem is changed to an unconstrained optimization problem and further constraints can simply add to the MDO process in future. So far main constraints are the intake air mass flow for begin of cruise, the distance between centre of gravity and pressure point for all calculated mission points, gross lift off weight and the resulting force in flight direction for all cruise points. As a disadvantage of this method a noisy objective function characteristic is expected.

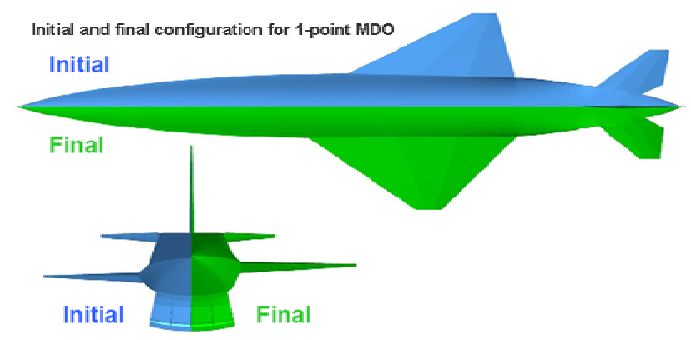

Fig. 8: $\quad$ MDO results for a 1-point, cruise, optimization (DLR-AS).

Since the development of the structural module is being carried out in parallel to the first MDO applications it is not included in the MDO results here discussed. A first 1-point MDO for begin of cruise is performed to validate the functionality of the tool. In every loop the mass estimation at the beginning of cruise gives the targeted lift for CFD calculations. Overall 13 geometrical design parameters, 4 for wing, 4 for horizontal stabilizer and 5 for fuselage are chosen. The result of the 1-point MDO by comparing initial and final design is shown in Fig. 8. The cruise range is increased by 10 percent due to increase of L/D and tank volume. The 1-point MDO then is extended to 3-point MDO by adding a transonic acceleration point at Mach 1.3 and the end of cruise point due to the critical trim condition mentioned above. Hence configuration mass at begin of cruise is now depending on transonic performance which determines fuel consumption during acceleration and climb. The number of design parameters is increased up to 22. Assuming the lift proportional to weight, constant cruise velocity and flight height, the basic range equation is integrated in a form that the aerodynamic performance at the end of cruise is included in the cruise range calculation. Figure 9 demonstrates the current characteristics of the 3-point MDO. The functionality of various configurations is shown as well as the optimizer capability leading out of a penalized system and increase objective 
function by 9 percent. At the moment the major issues that have to be considered during the MDO are the mandatory integration of the engine due to the lift increase, the identification of the end of cruise point with worst trim conditions and the low frequency lateral and vertical bending of the configuration due to the large dimensions.
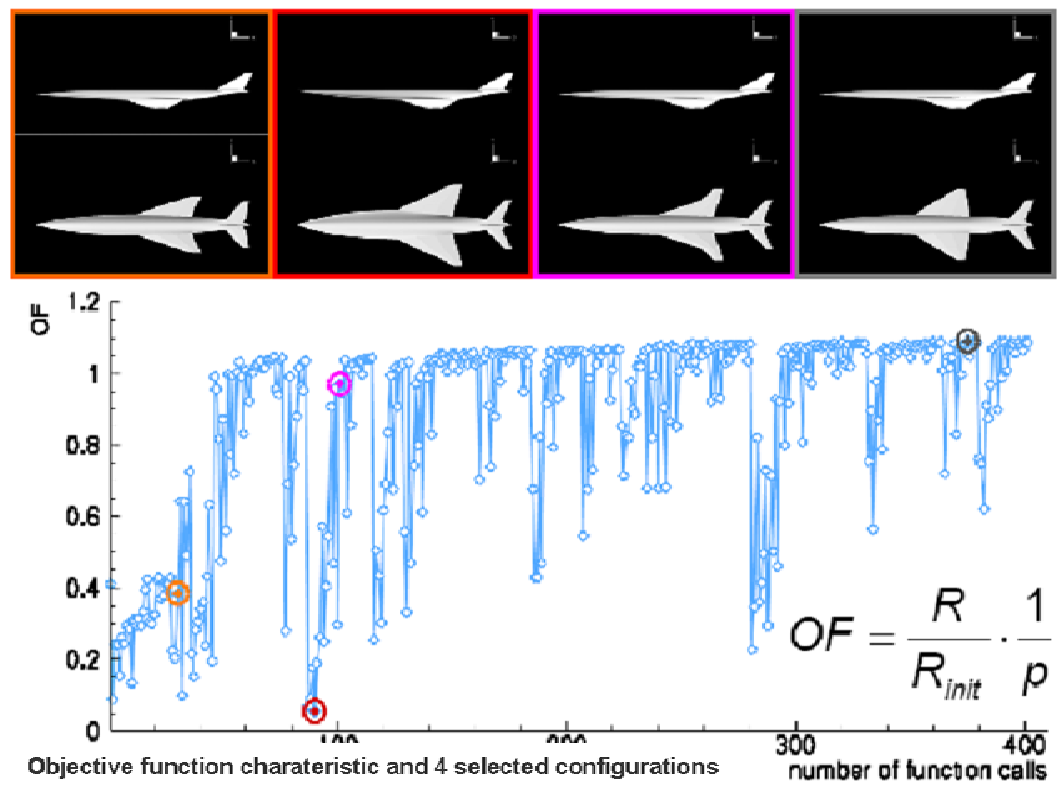

Fig. 9: $\quad$ MDO on-going results for a 3-point (acceleration, beginning- and end of cruise) optimisation. Top: configuration changes after arbitrary number of MDO loops. Bottom: MDO-convergence (DLR-AS).

\section{Propulsion Integration by Multidisciplinary Design Optimization}

ONERA, as a contributor to the MDO, focuses on the forebody and inlet design as they are closely integrated. The first stage consisted in designing a relevant inlet baseline. A detailed aero-propulsive performance of the configuration equipped with the inlets is assessed in order to set the reference for the MDO process. The baseline air-intake is designed using 2D-RANS calculations (Spalart-Allmaras turbulence model) on a structured mesh. A mixed compression intake is selected since it allows a good trade-off between kinetic energy efficiency at high Mach number and reduced cowl drag. In the selected baseline configuration, the flow is supersonically compressed by three external ramps extending between $45 \mathrm{~m}$ and $55 \mathrm{~m}$ downstream from the fuselage nose and the internal cowl profile. The flow compression is then achieved by a terminal normal shock and a subsonic diffuser (end of the diffuser at $X=65 \mathrm{~m}$ ). The upper wall internal profile is designed so as to cancel as much as possible the reflected shocks. Only a virtual terminal shock (VTS) is considered at this stage instead of considering complete more realistic throttling device which would require time consuming NS calculations. To take this VTS into account in the efficiency assessment an average one-dimensional flow field conserving the mass flow, momentum and total enthalpy fluxes of the two-dimensional flow has first to be calculated slightly downstream from the intake throat. With the proposed design, considering 4 rectangular intakes of $2 \mathrm{~m}$ width each, the engine demand is matched (425 $\mathrm{kg} / \mathrm{s}$ per intake). The average VTS Mach number is around 1.5. Neglecting the diffuser losses but taking into account the VTS, kinetic energy efficiency amounts to slightly above 0.96. Four modules of this baseline intake configuration are integrated into the ATLLAS M6 RD. The 2D pressure distributions along the external and internal walls are also used as an input for the structural model improvement. The MDO for the propulsion unit consists in finding an enhanced inlet geometry satisfying the following problem: total drag as objective function with minimum lift and inlet mass flow requirement as constrains. The overview of the corresponding process is illustrated in Fig. 10. It can be decomposed into two main parts which are the analysis module and the optimizer. The latter is based on a suitable algorithm, according to the optimization problem to solve. On the other hand, the analysis module provides the performance in terms of objective function and constraints values. A 16 variables parameterization is chosen in order to define the most appropriate design space of research of the optimum for the given optimization problem, see Fig. 11. The new mesh corresponding to a set of design variables is generated using a combination of volume mesh deformation techniques such as free form [9] or similar analytical linear deformations. Furthermore, an optimization algorithm based on a global (genetic algorithm) approach is chosen to search the optimum in the 
design space, which is typical for an optimization problem with a significant number of design variables. The optimization is performed using an automated PYTHON based program to ensure synchronized communication between the optimizer and the analyzer, while the CFD-RANS calculations are performed with the ONERA elsA solver [10] using a structured mesh.

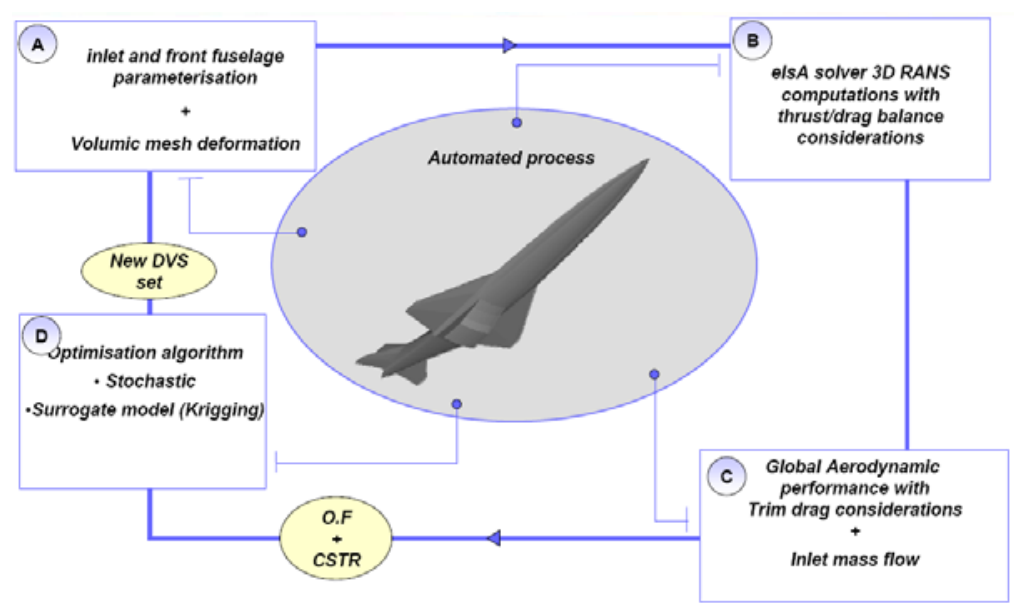

Fig. 10: MDO process for the propulsion integration (ONERA).

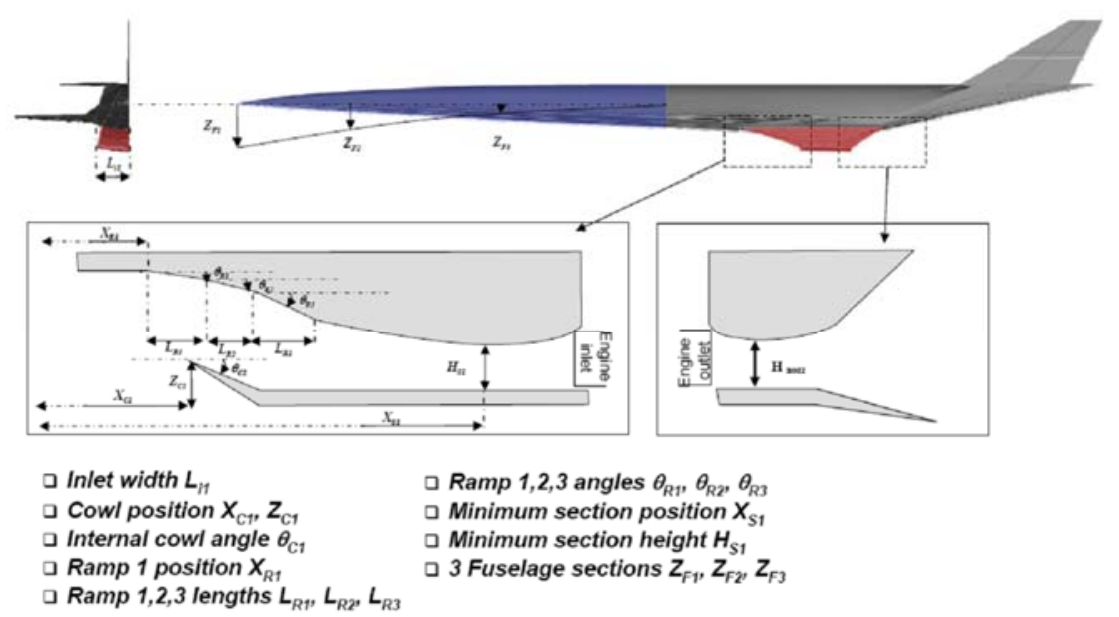

Fig. 11: MDO parameterization for the propulsion integration (ONERA).

\section{Structure Model \& Internal Layout}

One of the activities for the MDO processes described in the above chapters is the structural design. FOI is responsible for the structural model and analysis of the airframe and the intake. The structural design requirements are short load-paths and sufficient interior space so that structural members such as beams and frames can meet stiffness and strength-requirements without jeopardizing the weight budget. Stiffness requirements originate either from aircraft handling and aeroelastic considerations, including, for instance, flutter and control-surface authority, or from buckling constraints. Strength (stress) requirements depend on material selection, operating temperature and detail design. In the early design-phases it is important to find out what is driving the structural weight, for instance the slenderness of the fuselage or wing or the layout for principal load-paths. Further, an efficient interface to the aerodynamic surface-description has been created for the MDO-processes, taking into account flexibility with respect to design changes. This computational tool automatically creates a complete model for a structural finite element analysis suitable for the preliminary design. The input file is created by executing in a sequence nine 
programs: fuselage, wings, fuel-tanks, mass-distribution etc. The model consists of 4-node shell elements for cover plates while bar elements are simulating frame stations. Spars and stringers and rigid body elements are used for component connections while the fuselage tanks contribute to the bending-stiffness of the airplane. For FEM computations the numerical structure solver NASTRAN is used. As a forerunner to the MDO-process a sequence of FEM runs are performed, where the structural design is modified for each calculation in order to increase the lowest vibration natural frequency of the airframe, without increase of the total weight of the structure. Figure 12 shows the results of this preliminary structural analysis. It turns out the frequency for vertical fuselage-bending is very low which could cause flight-mechanics/control problems. On the other hand, the present structural design has sufficient flutter margin and no problem with aeroelastic divergence.

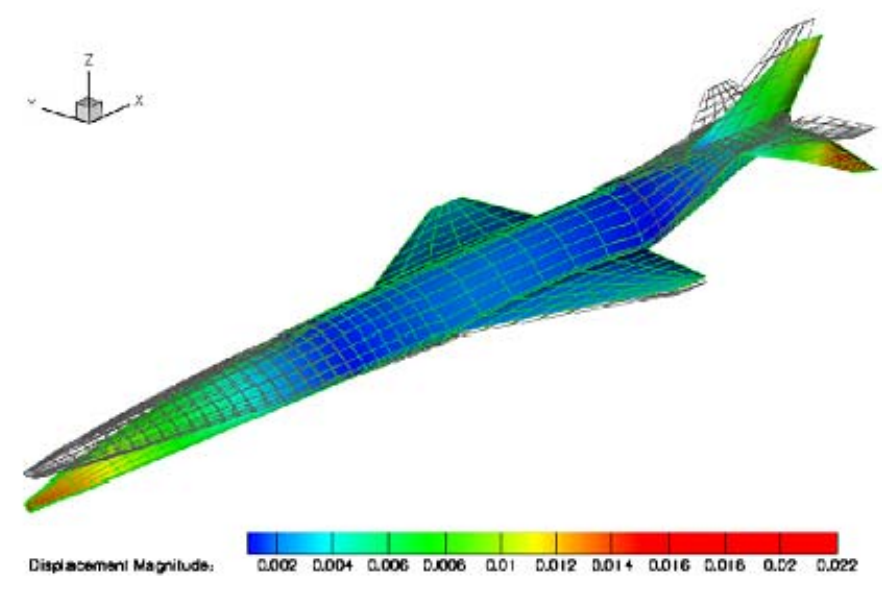

Fig. 12: Preliminary bending analysis of the aircraft' structure (FOI).

Also non-structural masses are distributed over the whole structure. The mass estimation is performed by determining the surface areas and the geometrical centre of gravity of these surfaces resulting from the geometry module. Every surface is loaded with a mass distribution and an additional fix mass which is not changed during the MDO. The initial mass budget of the ATLLAS M6 RD configuration provides the input while the updates are obtained from the changes on configuration geometry, as presented in Fig. 13-left, and from the changes on fuel charging, as is shown in Fig. 13-right. The location of the centre of gravity is updated as result of theses changes.
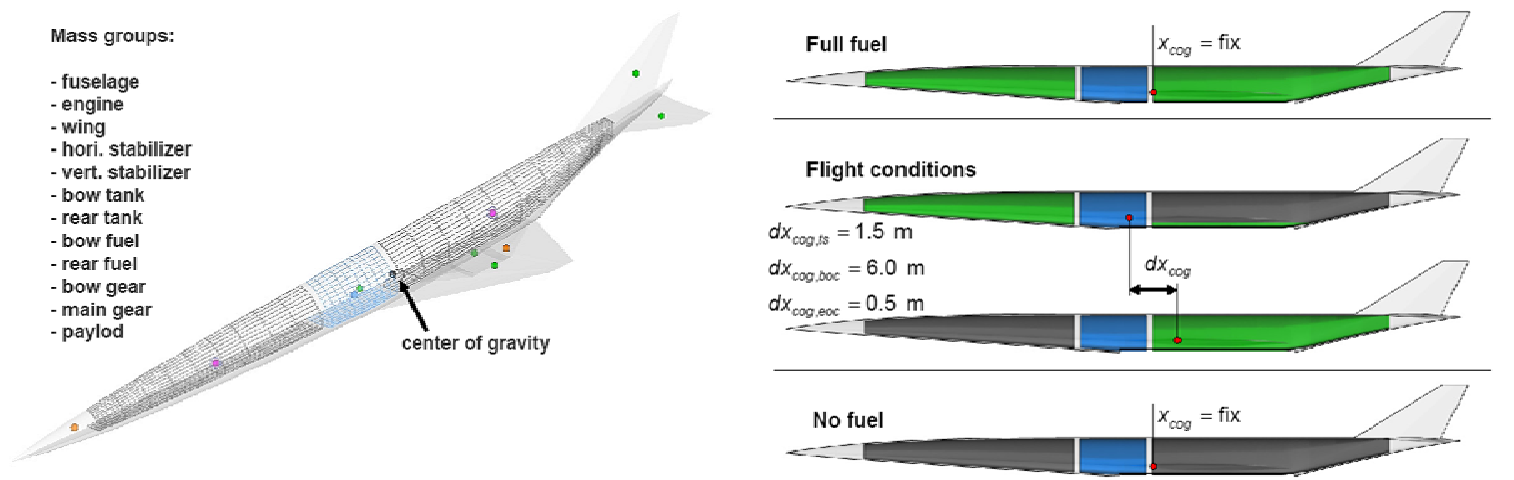

Fig. 13: Mass model left and variation of the centre of gravity location as a function of fuel charging (FOI \& DLR-AS).

The internal layout of the vehicle is responsibility of DLR-SART. The design of non-integral tanks has been done using a new Multi-lobe Tank Extension Module. This extension accounts for load factors, heat fluxes and fuel mass. The Program Tasks are (i) tank pre-designing (dimension mass); (ii) propellant feed-line design (dimension, mass, pressure Losses); (iii) tank filling (dimension, mass); (iv) tank-pressurization (integration of ODE for determination of the thermodynamic environment, pressurization gas mass, pressurization system mass). Further, special features for hypersonic aircrafts are included like (i) complex body / fuselage geometry as a result of the 
aerodynamic demands; (ii) need for storage of very large amount of low density propellant; (iii) need for highly efficient use of the internal volumes. The major design objectives are minimal number of input parameters but maximal flexibility and very fast generation of regular mesh under the assumptions that separating walls should be flat (due to stress consideration), intermediate parts of Multi-lobe tanks should be cylinders or cones and finally dome parts (incl. separating walls) should be independent from tank length. Typical examples of the geometry automatically generated by the new module for a symmetrical five-lobe large cryogenic tank are here demonstrated. The software is successfully used for a fast design of tanks containing $99050 \mathrm{~kg}$ of LH2 (assuming the fuel is stored under sub-cooled conditions of $15.25 \mathrm{~K}$ ) that fit quite well inside the airframe geometry (Fig. 14).

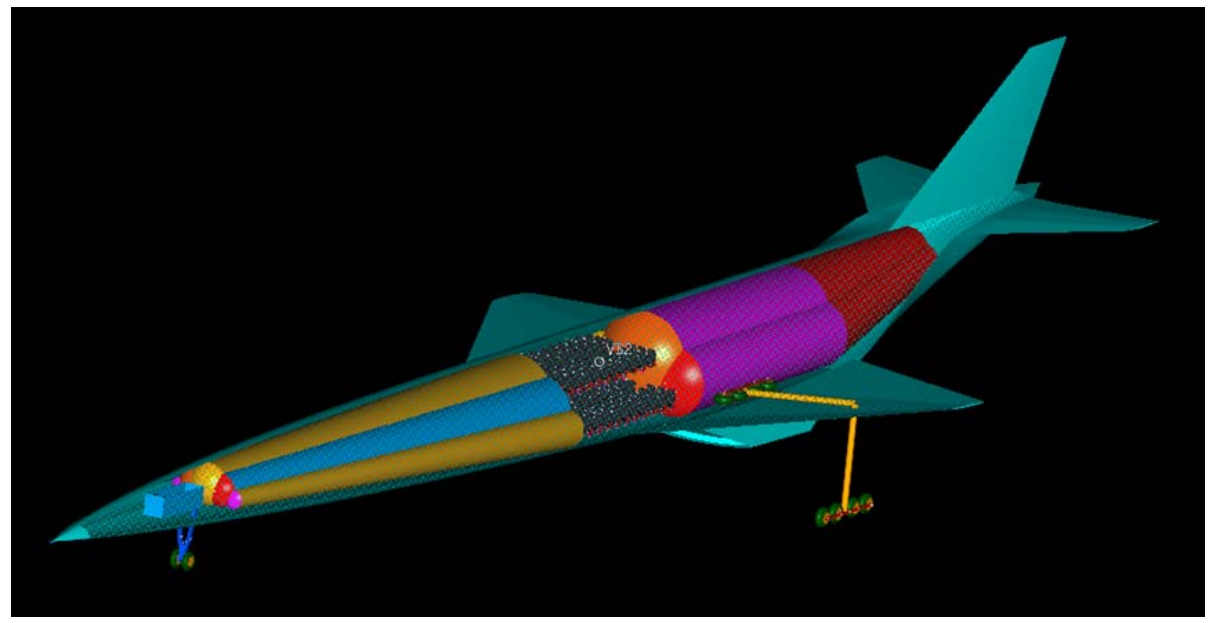

Fig. 14: A Multi-lobe Tank extension module is successfully used for fast design of the internal volume (DLR-SART).

\section{Sonic Boom Assessment \& Mitigation}

The major technologically challenging problem in the design of environmentally compatible high-speed cruise vehicles is the management of the sonic boom and the resulting reflection of the shock system on the ground. The sonic boom is a footprint of the aircraft wake in the far field. With the aircraft at high altitude the footprint is spread over a large area and energy considerations alone indicate that it should be a weak disturbance. However the human ear is very sensitive and pressure waves produced by supersonic aircraft like Concorde are too strong to allow supersonic overland flight. Here UPMC investigates the sonic boom ground impact for the ATLLAS M6 RD flying at Mach 6 cruise at a 28km altitude. Different options in the UPCM code are utilized to calculate ground track waveforms, sonic boom carpet, and limiting rays. All calculations are done for a rigid ground and account for pressure doubling due to the ground reflection. This assumption leads to an overestimation of sonic boom levels relative to a finite-impedance ground such as grass [11]. In addition to meteorological data, the other input to the sonic boom propagation code is the aircraft wave-form. The ATLLAS M6 RD near-field signature at a $28 \mathrm{~km}$ altitude is extracted from the DLR-CFD results by ONERA applying a multi-layer sonic-boom evaluation approach to calculate the ground pressure resulting from the supersonic flight. The method uses as input the CFD near-field pressure information, taken on cylinders parallel to the freestream location and passing through the vehicle forebody, at a distance of $0.15 \mathrm{~m}$ (Fig. 15). This short distance gives a distance-to-aircraft-length parameter of $\mathrm{R} / \mathrm{L}=$ 0.15. This wave-form may not be ideal for the acoustic code because it is extracted very close to the aircraft, whereas an $\mathrm{R} / \mathrm{L}=1$ is usually recommended. An ONERA in-house developed multipoles matching method [12] based on an azimuthal Fourier transform of the near-field pressures is employed to generate a locally axisymmetrical pressure signal that is then propagated to the ground through a standard atmosphere with the non-linear acoustic propagation code from UPCM.

Aircraft signatures are provided for azimuth angles of emission between $0 \pm$ and $180 \pm$ in steps of $5 \pm$. Sonic boom impact is estimated in terms of peak overpressure at the vertical of the flight track, front shock rise time, and lateral extent of the geometrical carpet. The first two parameters provide an estimation of the loudest boom likely to induce maximum annoyance, while the third parameter estimates the lateral impact of the boom during the cruise phase. The shock overpressure $\Delta \mathrm{p}$ is the maximum pressure at the shock, and the rise time $\mathrm{t}$ is defined as the time it takes for the amplitude to increase from $10 \%$ to $90 \%$ of the maximum. The rise time is a key parameter in sonic boom 
analysis because it is linked to human annoyance. The sharper the shock, the shorter the rise time, which leads to human perception of a louder, more annoying sound [12-13]. The first computations are ground track sonic booms, which result from the acoustic ray emitted at $0 \pm$, directly below the right path.

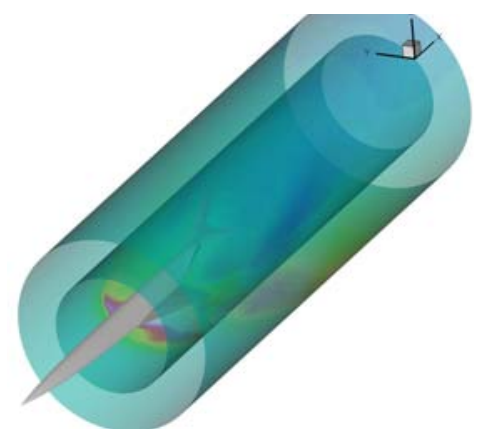

Fig. 15: CFD near field pressure footprint extraction from a DLR CFD solution (ONERA).

As a sonic boom propagates over long distances, it is strongly affected by the atmosphere and thus is dependent on meteorology and geographical location. The impact is quantified statistically, based on numerical simulations using an extensive meteorological database. To perform the statistical analysis of the variability of sonic booms for the configuration, UPMC has extracted meteorological data from the ERA40 database of the European Centre for Medium-Range Weather Forecasts (ECMWF) for the year 1993, at two geographical points near Le Havre (France), which was the beginning of the Concorde's supersonic flight between Paris and New York, and near Edwards AFB (California, USA), where most of the recent sonic boom flight tests have been performed. The two points also are characterized by a very different humidity and temperature (and hence absorption) near the ground level, due to Le Havre being on the seashore while Edwards is in the Mojave Desert. The sonic boom propagation predictions include ray tracing in a stratified atmosphere with horizontal winds, nonlinear distortion, atmospheric absorption due to classical thermo-viscous effects and rotational relaxation, and atmospheric absorption due to molecular vibrational relaxation of nitrogen, oxygen, and carbon dioxide. The sonic boom emitted in the vertical plane at a $0^{\circ}$ azimuth angle was computed every day and for two different flight directions, which demonstrate the effect of winds on propagation. The direction West is referred to as $0 \pm$, and East is referred to as $180 \pm$. Sonic boom carpets are also simulated systematically along with lateral distributions calculated once per month, using the full complement of azimuthal aircraft signatures to predict the area of ensonification at the ground. An example of such carpet computation is shown in Fig. 16. The carpet for Edwards at $0 \pm$ shows a mean carpet width of $148.4 \mathrm{~km}$, with a

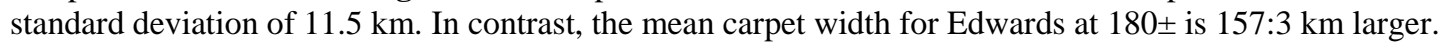

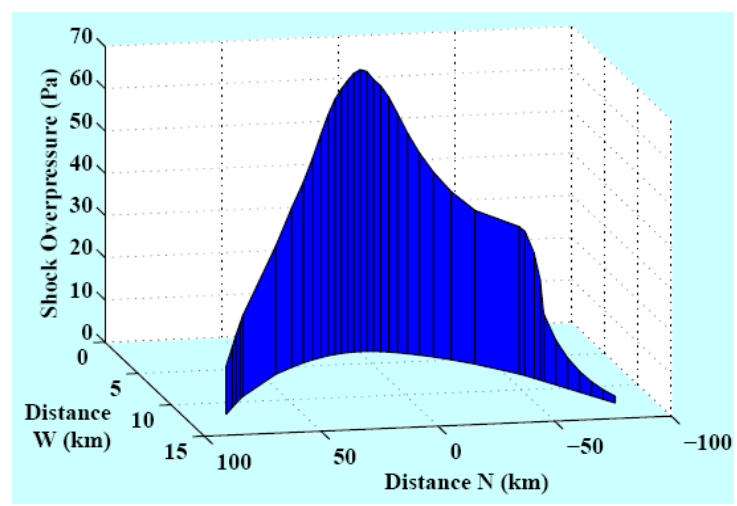

Fig. 16: Example of delta pressure carpet prediction (UPMC).

The standard deviation is also larger, $15.7 \mathrm{~km}$, indicating a greater variability. In a few cases, there are carpet widths which reach almost $250 \mathrm{~km}$. For Le Havre, the mean carpet width of $160.1 \mathrm{~km}$ at $180 \pm$ is larger than the 153.6 $\mathrm{km}$ at $0 \pm$. In addition, the standard deviation is larger at $180 \pm$. In comparison to Edwards, the Le Havre carpet widths are larger, most likely due to the stronger W-E winds above $20 \mathrm{~km}$ at Le Havre. While varying in direction 
throughout the year, the S-N winds at Le Havre are also stronger than those at Edwards. With standard deviations of 19.2 and $21.1 \mathrm{~km}$, there is also more variability in the carpet widths at Le Havre, which can be linked to the greater variability in wind direction below $20 \mathrm{~km}$. Key sonic boom parameters are compared to predictions for other aircraft configurations at Mach 1.6 and to a previous study for a Mach 2 aircraft [14]. The ground track sonic boom of the ATLLAS M6 RD reaches amplitude of approximately $65 \mathrm{~Pa}$, comparable to that of existing aircraft, most of which are comprised between 50 and $100 \mathrm{~Pa}$ (this last value being typical for the Concorde). As expected, the rise time is somewhat larger at Edwards (mean value $1.7 \mathrm{~ms}$ ) than at Le Havre (mean value $1.0 \mathrm{~ms}$ ) and in both cases shows a strong variability, the minimum and maximum values being separated by almost one decade. The ICAO standard atmosphere tends to slightly overestimate the sonic boom at the ground level. The carpet width also shows a significant variability, with larger values and more scattering at Le Havre due to stronger winds. Note that atmospheric turbulence is not included in the prediction model, and turbulence would increase the variability even further. Random fluctuations in temperature and wind velocity cause turbulent eddies which scatter sound energy from a wave propagating in the atmosphere, causing fluctuations in amplitude and phase of the sound wave. Experimental studies of spark-generated $\mathrm{N}$ waves to model sonic boom propagation through turbulence show that turbulence almost always decreases shock overpressures and increases rise times [15-17]. Thus it is believed that turbulence would generally decrease the sonic boom impact predicted here.

As a conclusion, the ATLLAS M6 RD configuration would induce at the ground a sonic boom level comparable to existing supersonic aircraft but covering a larger geographical area, due to a higher Mach and a higher altitude. As a consequence, overland supersonic flight by such a hypersonic vehicle is likely to be considered unacceptable by a significant proportion of the population, and hence justifies the necessity of other studies towards boom shaping and minimization with new aircraft designs. Here the study follows Seebass and George [18] who state that the sonic boom of an aircraft can be controlled by carefully designing its lift and cross-sectional area distribution. Seebass and George suggest creating a strong bow shock by blunting the body, which is expected to cause a penalty in aircraft drag. As the general design of the ATLLAS M6 RD is fixed, altering the overall lift distribution is not an option. Instead, the effect of aero-spikes is regarded. The characteristic of the $\mathrm{N}$ wave can potentially be modified employing a spike system on high speed vehicles which could significantly weaken and disperse the strong shock system. Generally, three types of spikes can be distinguished: (i) Physical spike; (ii) Mass deposition; (iii) Energy deposition. Physical spikes mean an actual attachment to the forebody of the aircraft. Mass deposition means ejection of matter to cause an effect in the incoming flow, also called aero-jet-spike or counter-flow jet. The third method encompasses flow manipulation by transferring energy to some point upstream of the aircraft, e.g. by means of laser, microwaves, electrical discharge, or external combustion, in order to heat or even ionize the flow. Calculations are carried out using DLR flow solver TAU. An inviscid equilibrium model is used. Since this study is concerned with forebody modifications, the computational domain spans the first 50m of the configuration, i.e. before the wing root, taking advantage of the symmetry of the aircraft. The computations show that the near pressure field can be altered by means of nose piece attachments, gas ejection or energy deposition. The aero-jet-spike behaves similarly to physical spikes while in terms of reduction of overpressure the jet outperforms the physical spikes. However, the aero-jet-spikes increases drag substantially and raise additional issues concerning system integration and propellant supply of the retro-rocket but it offers a flexible adaptation of flow manipulation in flight so as to adapt to different flight conditions. In addition to physical spikes and aero jet spikes, volumetric energy deposition is utilized in order to numerically study the effect of sonic boom mitigation. In Fig. 17 the pressure signature (Cp distribution) along the windward part of the line defined by the intersection of the symmetry plane and the exit plane of the computational domain is plotted. Here the pressure distribution resulting from the reference configuration without application of spikes or energy deposition is compared with the most efficient aero-jet-spike and one case utilizing energy deposition. The latter technique leads to a lower pressure distribution than the reference solution and the aero-jet-spike accompanied with a slight reduction in drag but a huge amount of energy (o[MW]) is required for this solution. It turns out that all investigated potential solutions do not produces the expected effects. As a matter of fact, the underlying theoretical work of Seebass and George is based on the linearized gas dynamic equations. Strictly, the theory is thus not applicable to hypersonic flight Mach numbers. Furthermore, no experimental data are available on hypersonic sonic boom mitigation based on these principles. Recent flight experiments have not exceeded a flight Mach number of 2.0 [19-20]. While the application of spikes to blunt bodies is a widely accepted and used method, no publications are available on the application of spikes to slender bodies. Also, no data are known on the behavior of spikes in a long sustained flight as envisioned here, particularly regarding heating and structural loads. Further, a complete optimized design of the whole airframe with respect to sonic boom mitigation is not planed in the frame of the present study but could be motivation for future researches. 

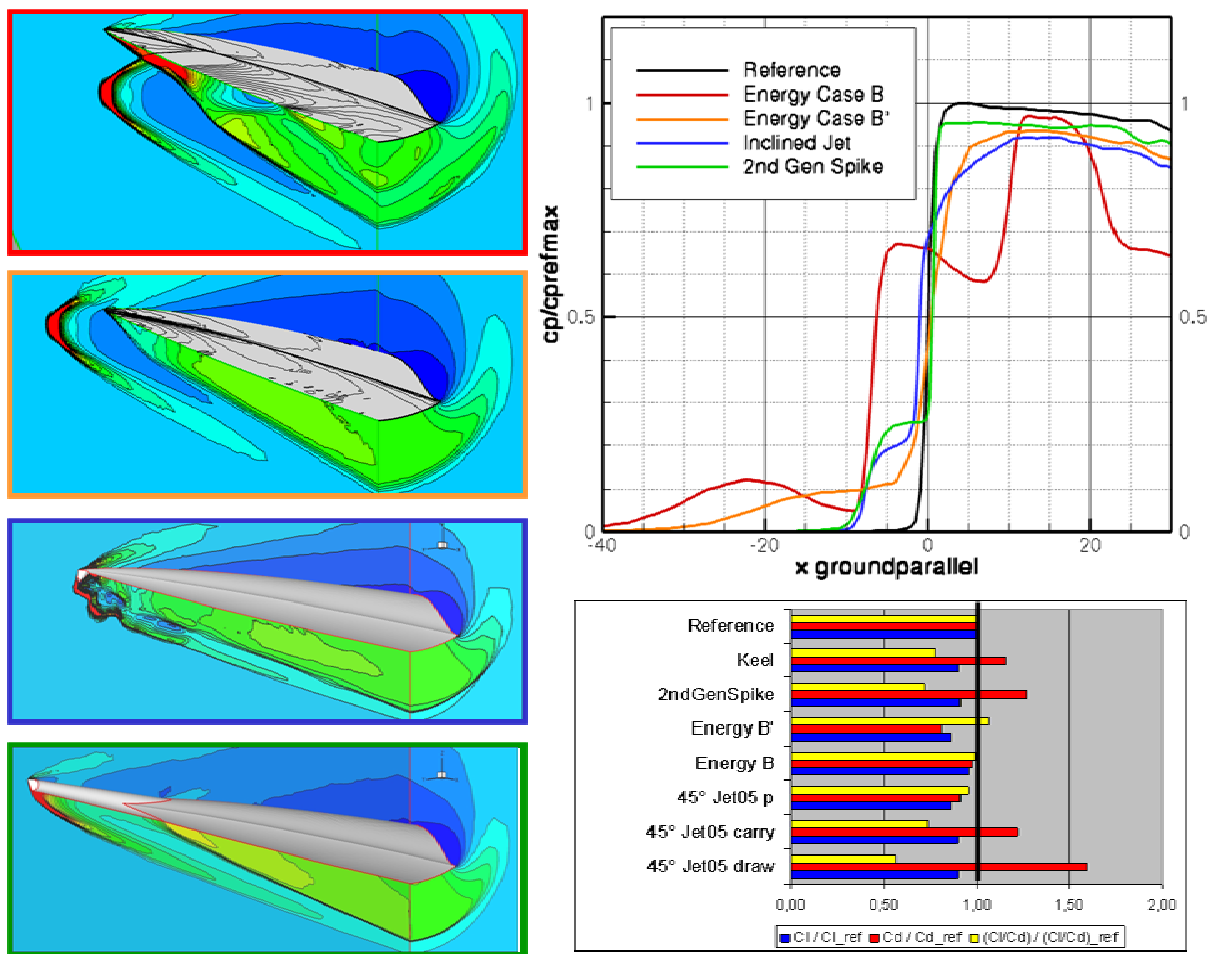

Fig. 17: Near pressure field modifications by spikes, aero-jet-spikes and energy deposition. Left from top to bottom: energy deposition case B; energy deposition case B', aero-jet-spike, $2^{\text {nd }}$ generation spike. Right top: pressure signature. Right bottom: aerodynamic performances (DLR-AS)

\section{Design Verification}

Since the final design of the airplane is based only on CFD results, an exhaustive CFD assessment exercise is being done by ESA-ESTEC taking advantage of the wind tunnel testing for similar configurations for which data is also available. Numerical solutions obtained with the CFD FASTRAN code of ESI GROUP for a HYCAT configuration are compared with available experimental data from literature [2], as is shown in Fig. 18 where pressure contours are plotted on the vehicle-surface of the wind tunnel tests configuration ( $5^{\circ}$ incidence, Mach 6 ).
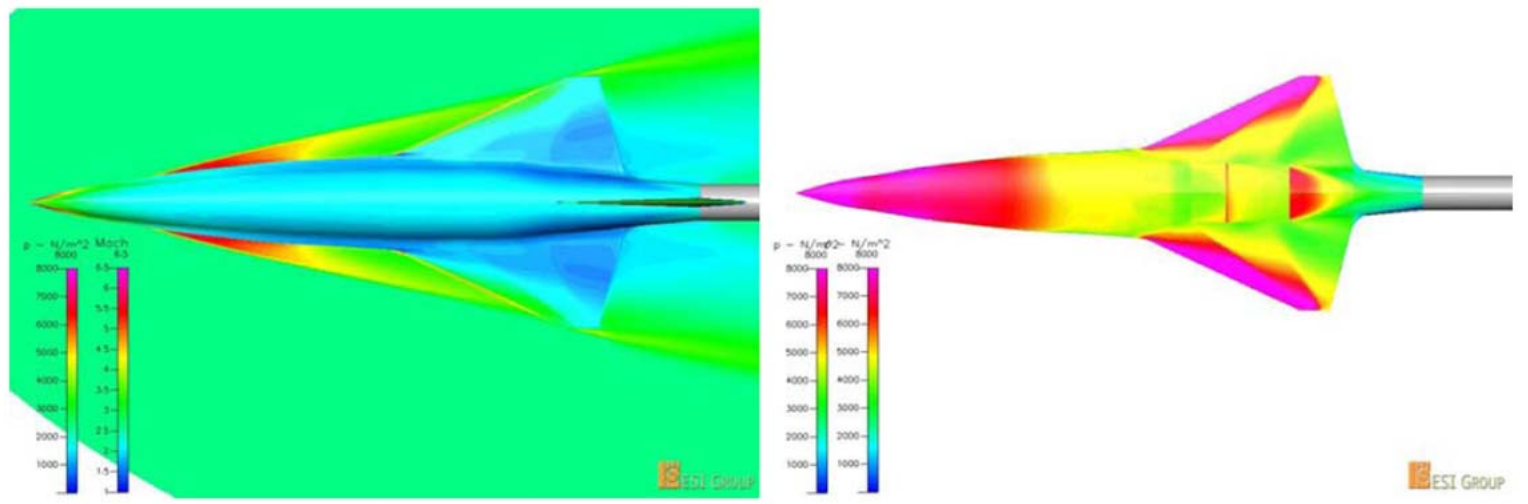

Fig. 18: Computed surface pressure distribution for the HYCAT configuration. Left: leeward side. Right: windward side (ESA-ESTEC).

The signature of the vortex from the chine over the upper wing is apparent in the top figure and is evidenced by the low pressure region visible on the aft wing in the middle figure. The high pressure region in the nose, due to 
fuselage camber, drives the longitudinal pitch characteristics of the configuration. The on-going test matrix includes more than 100 computations, covering longitudinal and lateral coefficients as well as the assessment of the viscous effects. Figure 19 show pitching moment coefficients with three elevon settings from the wind tunnel cases. The value derived from the current CFD cases are over plotted for comparison. The wind tunnel data for $0^{\circ}$ elevon deflection demonstrates significant differences from the Euler CFD prediction. No distributed pressure data from the wind tunnel tests exists, however; a working assumption is that the after-body flow is significantly influenced by viscous effects missing from the Euler simulations. Confirmation on this point is partially given by the viscous CFD calculations where the deviation from the wind-tunnel results is reduced in comparison. Inclusion of additional parameters (e.g. differential elevon positions) may be foreseen in order to better characterize the respective configurations. The defined plan will allow a deeper understanding of the trim behavior and to a lesser extent the lateral stability characteristics of the chosen configuration. Care needs to be taken for the extrapolation to flight as some significant differences are present in the wind tunnel tests / CFD comparison. However the wind tunnel tests are far from fully representative in terms of Reynolds Number. The exercise is primarily to validate chosen CFD tool(s). Finally, a Cross validation (code-to-code) will be made with the DLR TAU code used in the MDO process in order to identify any major differences between the Euler methodology employed and the full viscous solutions.

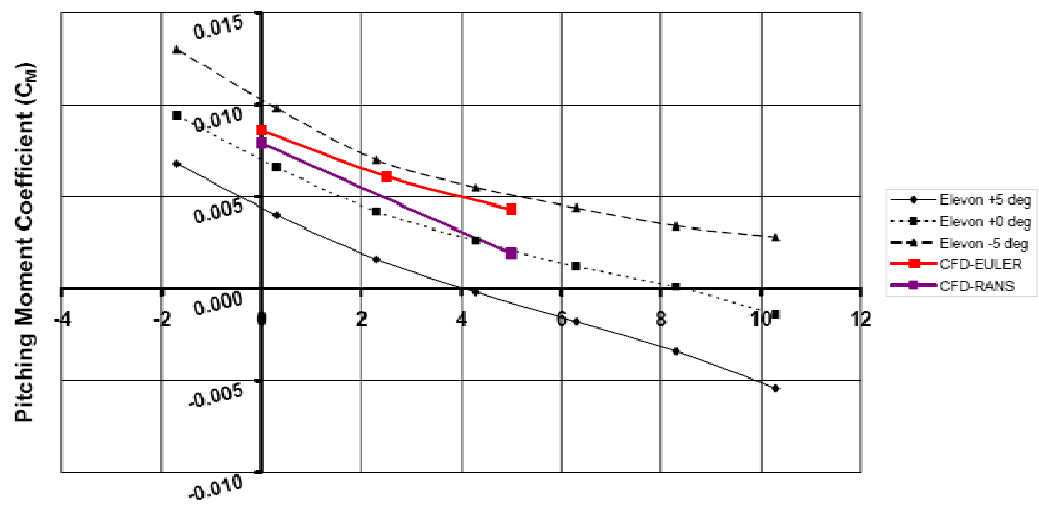

Fig. 19: Computed pitching moment coefficient vs. AoA for the HYCAT configuration (ESA-ESTEC).

\section{Conclusions}

The present paper summarises a conceptual study on the possibility to transport 200 passengers over a distance of about $7000 \mathrm{~km}$ in a nominal point-to-point mission over the Atlantic (either London-New York or London-Rio) at a cruise Mach number of 6 and an altitude about $30 \mathrm{~km}$. The aim of the study is not to design a specific airplane but to explore today's state of the art technology limits to realize such kind of concept, i.e. to identify if such a mission could succeed today. Because of the challenge the mission poses, its is being highly optimised regarding the major disciplines involving aerodynamics, flight-mechanics, propulsion-integration and structure by means of MultiDisciplinary Optimisation (MDO) tools. Two different MDO process, one for the airframe and one for the propulsion-integration are applied. The study includes a flexible structural model and provides engine parameters, internal layout (particularly tanks), mass distribution and trim considerations. The environmental impact is being analysed in terms of the resulting sonic boom, while mitigating devices are evaluated. The study indicates that today the available technology provides with sufficient maturity to accomplish with the mission in areas like aerodynamic and thermal resistance materials but in others like sonic boom mitigation it is required a deeper insight in the physics. Finally while the present investigation clear identify that complex designs involving large amount of variables from different disciplines could be only possible via MDO/MDA strategies, today such processes still suffer on lack of robustness of the involved tools.

\section{Acknowledgment}

This work is being performed within the 'Aerodynamic and Thermal Load Interactions with Lightweight Advanced Materials for High Speed Flight' project ATLLAS, coordinated by ESA-ESTEC and supported by the EU within the $6^{\text {th }}$ Framework Program, Aeronautic and Space, Contract no.: AST5-CT-2006-030729. 


\section{References}

[1] Morris, R.E., Brewer, G.D., Hypersonic Cruise Aircraft Propulsion Integration Study Volume I/II, NASA Contractor Report CR-158926-1, 1979.

[2] Elison, J.C., Investigation of the Aerodynamic Characteristics of a Hypersonic Transport Model at Mach number to 6, NASA TN D-6191, 1971.

[3] Dittrich, R., Longo, J., Preliminary Design of a Mach 6 Configuration using MDO Approach, Proceedings of the 16. DGLRFach-Symposium der STAB, Aachen, Germany, November 2008.

[4] Schwamborn D., Gerhold, Th., Heinrich, R., The DLR TAU-Code: Recent Applications in Research and Industry, Proceedings of the European Conference on Computational Fluid Dynamics, ECCOMAS CFD 2006.

[5] Piegl, L., The NURBS Book, 2nd Edition, Springer, 1997.

[6] CENTAUR Version 7.5 B1, CentaurSoft, www.centaursoft.com, 2007.

[7] SynapsPointer Pro 2, Synaps Ingenieur-Gesellschaft mbH, Bremen, Germany, 2003.

[8] Rowan, T., Functional Stability Analysis of Numerical Algorithms, Thesis, Department of Computer Sciences, University of Texas at Austin, USA, 1990.

[9] Coquillart, S., Extended free-form deformation: a deformation sculpturing tool for 3D geometric modeling. Computer Graphics (SIGGRAPH '90) 24(4), 187-196

[10] Cambier, L. and M. Gazaix, M., elsA: An Efficient Object-Oriented Solution to CFD Complexity, 40th AIAA Aerospace Science Meeting and Exhibit, Reno, Jan. 2002.

[11] Coulouvrat, F., Sonic boom in the shadow zone: A geometrical theory of diffraction, J. Acoust. Soc. Am. 111, 499-508, 2002

[12] Page, J., Plotkins, J., An efficient method for incorporating CFD into sonic boom prediction, AIAA paper AIAA-1991, 1991

[13] Zepler, E., Harel, F., The loudness of sonic booms and other impulsive sounds, J. Sound Vib. 2, 249-256, 1965.

[14] Blumrich, R., Coulouvrat, F. and Heimann, D., Meteorologically induced variability of sonic-boom characteristics of supersonic aircraft in cruising flight, J. Acoust. Soc. Am. 118, 707-722, 2005.

[15] Lipkens, B., Blackstock, D, Model experiment to study sonic boom propagation through turbulence. Part I: General results, J. Acoust. Soc. Am. 103, 148-158, 1998.

[16] Lipkens, B., Blackstock, T., Model experiment to study sonic boom propagation through turbulence. Part II: Effect of turbulence intensity and propagation distance through turbulence, J. Acoust. Soc. Am. 104, 1301-1309, 1998.

[17] Ollivier, S., Blanc-Benon, P., Model experiments to study acoustic N-waves propagation through turbulent media, in 10th AIAA/CEAS Aeroacoustics Conference, 1355-1367 (American Institute of Aeronautics and Astronautics, Reston, VA), 2004.

[18] Seebass, R., George, A., Sonic-boom minimization. Journal of the Acoustic Society of America, 51:686-694, 1972.

[19] Haering, E., Murray, E., Purifoy, D., Graham, D., Meredith, K., Ashburn, C., Stucky, M., Airborne shaped sonic boom demonstration pressure measurements with computational fluid dynamics comparisons. Proceedings of the 43rd AIAA Aerospace Sciences Meeting and Exhibit, AIAA-2005-9, Reno, USA, 2005.

[20] Howe, D., Improved sonic boom minimization with extendable nose spike. Proceedings of the 43rd AIAA Aerospace Sciences Meeting and Exhibit, Reno, USA, 2005. 